\title{
Customer Perceptions of Skills of Agents in Effectively Managing Their Needs within a Call Center
}

\author{
Devina Oodith \\ College of Law and Management Studies, University of KwaZulu-Natal, Durban, South Africa \\ oodithd@ukzn.ac.za
}

\begin{abstract}
The world's dynamics and demands of employment and production have evolved over the past decade. Human resources has today become the single largest unrestrained resource and many firms are striving to enhance competence and interaction between its customers and itself via the customer call center through enhanced skills, knowledge, ability and attitude by fostering better interpersonal skills and through the promotion of training and development of their call center agents. This study was undertaken in EThekwini (Durban), South Africa and was conducted within a Public Sector service environment comprising of four major call centers employing a total of 240 call center agents. Using simple random sampling, 220 customers were drawn from all consumers subscribing to e-billing in EThekwini (Durban). Data for the customer sample was collected using a precoded, self-developed questionnaire whose psychometric properties were statistically determined. Data was analyzed using descriptive and inferential statistics. The results specify that agents were unsuccessful in handling customers' needs timeously and efficiently and that most customers felt burdened by being transferred to other agents due to the incompetence of original agents in handling their queries/complaints. Furthermore it was found that there was an overall lack of empathy from agents in following-up after a customer communication to ensure that the customer was satisfied with their experience within the call center. Based on the results of the study recommendations have been made to manage the interaction between the customers and call center agents more competently and efficiently.
\end{abstract}

Keywords: Call center agents, knowledge, ability, attitude, interpersonal skills, training and development

\section{Introduction}

This study assesses customer perceptions of the skills required by call center agents in effectively managing their needs during their interaction with the call center. In particular, it critically evaluates the skills, knowledge, ability, and attitude of agents in executing their duties, their level of interpersonal skills when interacting with customers and finally their level of training and development acquired to perform these tasks. It was hypothesized that there exists significant intercorrelations amongst the sub-dimensions of human resources (skills, knowledge, ability, attitude, interpersonal skills and training \& development) required by call center agents for effectively managing customers' needs. The influence of the biographical profiles on these perceptions was also appraised. It was hence hypothesized that customers varying in biographical profiles (gender, age, race, educational qualifications) significantly differ in their perceptions of the human resources skills required by call center agents to effectively manage their needs. Lucas (2005: p. 4) defines customer service as "the ability of knowledgeable, capable, and enthusiastic employees to deliver products and services to their internal and external customers in a manner that satisfies identified and unidentified needs and ultimately results in positive word-of-mouth publicity and return business".

A critical marketing activity is developing products and services that are able to satisfy consumers' needs and wants. Consumer research is able to provide answers to what a consumer is looking for in terms of the core product attributes, the advertising media that are likely to have the greatest impact, as well as prices of the product (Hoyer \& McInnis, 2001). According to Lucas (2005), there has been a shift in the service economy and some of the factors contributing to this are the increased efficiency in technology where activities like telemarketing and internet shopping has evolved and continues to expand. Some of the societal factors include more women entering the workforce giving rise to changes in their traditional roles; hence, there is a need for the tasks provided by housewives to now be provided by service providers. In South Africa there is a more diverse population entering the workforce bringing with them new ideas, values, needs and expectations of the needs of the groups that they represent. Lucas (2005) also found that customers have a greater desire to use their leisure time more efficiently, and with dual income families there is a greater degree of disposable income available to demand services such as dog walker's, garden services and laundry services among others. Education also impacts hugely on customer service as customers are well informed on 
price, quality and value of products and services and therefore, have a high expectation of the quality of service received. The last decade has also seen a drastic growth in E-commerce and the way customers conduct business via the internet from shopping to surfing the net for information on goods and services. This trend has placed an increasing demand on the creators of these innovative sites to provide a greater degree of customer service to customers without physically coming into contact with a customer.

The Services Marketing Mix: The traditional marketing mix, made up of the 4 p's, constitutes the total offering to consumers. The 4 p's according to Lamb et al. (2000) are the product (the basic service or good, including packaging), its price, the place (where the product is made available to the consumer or the distribution channels) and promotion (marketing communication, advertising, public relations and personal selling). According to Rust et al. (1996), managers have found that the traditional 4 p's of marketing do not adequately describe the key aspects required to carry out the job of a service employee. Zeithaml et al. (2006) suggest that the unique requirements of selling services require the addition of 3 more p's:

- People: In administering a service, personal interaction between customers and employees is required as these interactions affect the customers' perception of service quality. Friendliness, knowledgeability and helpfulness can have a direct impact on the customers' perception of service quality (Rust et al. 1996). Therefore, human resource management policies and practices are considered to be of high importance when delivering quality services.

- Process: Zeithaml et al. (2006, p. 27) define process as "the actual procedures, mechanisms, and flow of activities by which the service is delivered - the service delivery and operating systems". The actual delivery of the service gives customers a framework on which to assess the service (Lovelock, 2001).

- Physical evidence: Zeithaml et al. (2006, p. 27) best describe physical evidence as "the environment in which the service is delivered and where the firm and customer interact, and any tangible components that facilitate performance or communication of the service". This can include tangible representations such as brochures, letterheads and business cards. It can also include the physical facilities where the service is executed namely, the services cape. In other cases like the call centre for example, the physical facility is irrelevant to the customer.

In addition to the seven P's of services marketing there is also a four R model in marketing comprising of research, recognition, reputation and relationship. Any marketing that a firm does should focus on at least one or more of these R's.

- Research: Since research is often very expensive many firms fail to conduct any form of research activity. However, there are a number of cost and time effective research strategies that can be carried out such as customer surveys, interviews and secondary research.

- Recognition: Awareness of a firm in the markets they serve is critical for success. Mechanisms to create recognition include company logo, brochures, web sites and branded merchandise.

- Reputation: A good reputation is important and it is the lifeblood of a service firm. Reputation is a key indicator of quality and trustworthiness. Word-of-mouth communications, customer testimonials and stories help spread the word.

- Relationship: Relationships between the firm and their customers, suppliers, employees and the community at large are important to its ability to succeed. Some examples that enhance relationships include an employee newsletter, sales training tools and materials for channel partners and social events for customers (4 - R Marketing LLC, 2009).

The Customer Service Environment: The components of the customer focused environment consist of organisational culture, human resources, product deliverables, delivery systems and finally service.

- The Customer: The key component in a customer-focused environment is the customer as all aspects of the service organisation tend to revolve around the customer. The customer is the heartbeat of the organisation and without him or her there is no reason for the business to operate. Listening to customers and observing their behaviour enables a firm to meet their customers' needs (Cant, Brink \& Brijball, 2006). There are two types of customers, namely, internal and external customers. Internal customers can include co-workers, employees from other departments or branches and other people who work within the same organisation (Lucas, 2005). External customers may be 
current or potential customers or clients and they are the people who actively seek out the products or services offered by the organisation.

- Organisational Culture: Lucas (2005) defines the organisational culture as the experiences encountered by the customer. Organisational culture is made up of a collection of subcomponents, each of which contributes largely to the service environment. There must be cultural compatibility and firms should not impose their culture on customers or partner firms (Donaldson \& $0^{\prime}$ Toole, 2002).

- Human resources: In order for firms to operate optimally they must take great care in recruiting, selecting and training qualified people; hence, their human resources function becomes critical. Without motivated, competent workers, planning policy and procedure change or systems adaptation will not make a difference in customer service. Employees who are skilled, motivated and enthusiastic about providing service excellence are hard to find and are appreciated by employers and customers (Lucas, 2005). Face-to-face encounters are central to service delivery (Gabbott \& Hogg, 1998). One of the eight principles of "Batho Pele" stresses the need for courtesy by staff in interacting with customers. This principle goes beyond the need for a 'smile' or a 'thank you' and requires service providers to be courteous and respectable at all times (The Department of Public Service and Administration, 2001).

- Products / Deliverables: The product / deliverables may be a tangible item manufactured and distributed by the company (Lucas, 2005). However, there are two areas of customer satisfaction or dissatisfaction, namely, quality and quantity.

If customers receive what they perceive as a quality product or service to the level that they expected, and in the time frame promised they will likely be satisfied. But if the product sold was inferior or the service provided was perceived as being of an inferior quality then that customer will be dissatisfied (Zeithaml \& Bitner, 2003). Government's principle of "Batho Pele" reiterates that setting service standard principles is very important and customers need to be included in this process in order to establish acceptable benchmarks against which service delivery will be measured (The Department of Public Service and Administration, 2001).

- Delivery Systems: In deciding on an appropriate method of delivery to adopt Lucas (2005) suggests that the following should be taken into consideration:

> Industry standards: How are competitors currently delivering and are the firms' current delivery standards in line with those of our competitors?

$>$ Customer expectations: Do our customers expect delivery to occur in a certain manner within a specified time frame? Are alternatives available?

$>$ Capabilities: Do existing or available systems within the firm and industry allow for a variety of delivery methods?

> Costs: Will providing a variety of techniques add real value or perceived value at an acceptable cost? If there are additional costs, will consumers be willing to absorb them?

$>$ Current and Projected requirements: Are existing methods of delivery, such as mail, phone and face-to-face services meeting the needs of the customers presently and will they continue to do so in the future?

An analysis of the delivery systems serves as an indicator of what standards the firm should be aspiring to attain. It also provides insight into what competitors are doing and provides a framework on what measures need to be put into place to improve the existing resources in order to provide a better level of service.

- Service: Service is the manner in which the employer and employees treat the customers and each other as they deliver their product(s) or other deliverables. Employees are thus, privileged as they mediate between the firm and its customers (Gabbott \& Hogg, 1998). Many firms provide training for front-line staff to be able to service the customer such as telephone etiquette, complaint handling, coping skills when dealing with confrontational customers and comprehensive manuals equipping staff with sufficient information to be able to resolve queries or complaints on the first call. As a means of motivating staff to continually give off their best at all times firms provide incentive bonuses in recognition of outstanding work by their employees. 
Strategies for Influencing Customer Perceptions: Outlined below are a few very critical components of service delivery that are needed to ensure that the organisation is in a better position to cater for the needs of the customer. It is important to measure and manage customer satisfaction and service quality in customer focused firms continually (Zeithaml \& Bitner, 2003). Many firms have likened their customer satisfaction measurements to employer training, reward systems and leadership goals as all of these have direct spin-off effects for overall performance efficiency.

Furthermore, firms should aim for customer quality and satisfaction in every service encounter. Zeithaml et al. (2006) stress that in order to achieve this objective firms must have clear documentation of all points of contact between themselves and the customer. Once this is done they then need to develop an understanding of customer expectations for each of these encounters so that strategies can be built around meeting these expectations. Five themes have been identified to cope with satisfaction or dissatisfaction in service encounters:

- Plan for effective recovery: If a customer has experienced dissatisfaction on the first try then the firm has to aspire to do things correctly the second time to avoid the same situation from occurring. The service process has to be redesigned to identify the cause of the service failure. A recovery strategy must be put into place to create satisfaction for the customer (Zeithaml et al., 2006).

- Facilitate adaptability and flexibility: Agents need to know when and how a system can be flexed and why particular requests cannot be granted. Thorough knowledge of the service concept, service delivery systems and standards must be communicated to employees, to enable them to be flexible when dealing with customers without overstepping their levels of authority.

- Encourage spontaneity: Firms must encourage spontaneity and discourage negative behaviour amongst employees. Recruiting employees with strong service orientations is one way of doing this. Strong service culture, employee empowerment, effective supervision and monitoring and quick feedback to employees will also encourage spontaneity.

- Help employees cope with problem customers: Management and employees need to accept that the customer is not always right and will not always behave in an acceptable manner. Employees need appropriate coping and problem solving skills to handle difficult customers as well as their own feelings in difficult situations (Zeithaml et al., 2006).

- Manage the dimensions of quality and the encounter level: Although the five dimensions of service quality are generally applied to overall quality of the firm, it is possible to relate them to each individual encounter.

Oneayso (2007) conducted empirical testing to ascertain if there was a long run equilibrium relationship between customer dissatisfaction and complaints behaviour. Research shows that there has been an increasing interest in consumer dissatisfaction and complaint behaviour, with the main reason for this being attributed to the need for managers to maximise their customer retention by minimising customer dissatisfaction through better quality offerings (Lovelock, 2001; Rust et al., 1996; Zeithaml et al., 2006). Oneayso (2007) thus concluded that indeed there is an equilibrium relationship between customer dissatisfaction and complaints behaviour. Organisations, however, have to invest in a strong service recovery process in order to turn this dissatisfaction around. The service recovery process is now gaining momentum and is being used as a superior strategic asset to compete with competitors.

Listening to the Customer: It cannot be stressed enough that finding out what the customer expects is critical to providing quality services (Zeithaml et al., 2006). The quality of listening has a paramount impact on the quality of services (Lovelock, 2001). According to Peters \& Waterman (1982), there are many examples of senior executives of companies like Hewlett-Packard, McDonalds and Disney spending significant time in the field, taking sales roles or those of cleaning and selling tickets to be more in touch with their customers and to actually listen closely to what their expectations of services are. Oakland \& Beardmore (1995) have found that the most common technique for listening to customers is satisfaction surveys. Goodman, Broetzmann \& Adamson (1992) identified three problems encountered when using such surveys:

- The interpretation of the meaning of dissatisfaction measures proves to be a difficult task.

- The lack of analysis of market actions which result from satisfaction levels.

- The inability to identify sources of satisfaction or dissatisfaction. 
Oakland \& Beardmore (1995) suggest that satisfaction cannot be measured in a vacuum; measurements of expectations have to be included in order to contextualise the result. For example, a firm's overall customer satisfaction rating of 8 out of 10 tells management nothing of what the customers' expectations were. If their expectations were high, than a score of 8 would indicate dissatisfaction. Surveys do not attempt to measure the market actions of customers' dissatisfaction and this can mislead management. For example, the majority of customers may be satisfied with a product or service but failure to ask about market intentions like 'would you buy this product again?' or 'would you recommend the product to a friend?' might convey a less accurate picture of satisfaction to management. Goodman et al. (1992) conducted research of a US retailer and found that forty six percent of the respondents found faults that potentially hampered the service experience at the store but nobody complained to anyone as they perceived that nothing would be done it they complained; hence, the inability to identify sources of satisfaction or dissatisfaction.

The Ten Commandments of Customer Service: According to BizAssist Technologies (PTY) Ltd (2009), the following ten principles or commandments should be strictly adhered to in order to avoid a situation of customer service failure or customer dissatisfaction from occurring. These Ten Commandments are as follows:

- Know who is boss: You are in the business to service customer needs and this can be done only through listening to them.

- Be a good listener: Stirtz (2010) reiterates the success of Magic Johnson when he opened up a theatre in partnership with T.G.I. Friday's. This theatre was situated in the city and Magic found that these customers did not go to the movies and then to dinner, as compared to those who lived in the suburban areas normally would, but preferred to have dinner at the movies. So he introduced the sale of hot dogs at the theatre which proved to be a huge success.

- Identify and anticipate needs: The more you know your customers, the better you are able to anticipate their needs. Bannatyne (2010) has found that customers are opting to interact with firms via social networking sites such as Twitter and Facebook.

- Make customers feel important and appreciated: Treat each customer as an individual. Always use their names and find ways to compliment them. Vodafone and Virgin Media are using social networking as a key part of their customer services.

- Help customers understand your system: If customers do not understand the firm's system for getting things done they become confused, impatient and angry. Take the time to explain the system to them.

- Appreciate the power of "yes": Always look for ways to help the customer. Assure them that you can accede to their requests. Always fulfil your promises to them.

- Know how to apologize: Apologize when something goes wrong. The customer may not always be right but the customer must win. Make customer complaints simple and always value complaints.

- Give more than expected: Think of ways to elevate the firm and stay ahead of the competition. For example, what can you give customers that they cannot get elsewhere? And what can you do to follow-up and thank people even when they do not buy? Miller (2010) stresses that firms spend millions of rands in expensive advertising campaigns but none of these firms actually take time out to thank patrons for their loyalty and support.

- Get regular feedback: Encourage and welcome suggestions about improving your service. For example, Pick n Pay always invites customers to participate in quick surveys prior to exiting the store to enquire about the customer's service experience with a view to improving service delivery.

- Treat employees well: Employees are your internal customers and need to be appreciated. Thank them and let them know how important they are. Treat them with respect.

Skills, Knowledge, Ability and Attitude of Call Centre Agents: Theron, Bothma \& Du Toit (2003) highlight the following characteristics which they feel are critical skills that customer service employees should possess. These characteristics include:

- Coming to work regularly because if the customer service employee is away often and if interactions are handled by someone else, this may cause problems especially if the other person is inefficient.

- Be on time and never keep customers waiting. 
- Take pride in work and display confidence. Professionals care about what they do and should strive to teach customers new things (Snow, 2007). Have a positive mental attitude as there is always a negative environment created when customers lodge complaints but staff must maintain a positive mental attitude (Cavitt, 2010).

- Be affable and knowledgeable as this is the quickest way to diffuse a tense situation especially if the other person is being rude or is angry (Brown, 2007; Cavitt, 2010; Snow, 2007).

- Be interested and listen carefully to the problem and try to resolve it as these are the traits of a customer service superstar according to Cavitt (2010). Take responsibility by being responsive and always ensure a satisfactory end to the matter (Snow, 2007).

- Follow up with the customer to enquire if they were satisfied with the outcome. Be assertive as this is an unfortunate situation but sometimes although a solution is presented it may not be the solution that the customer wants. A good employee will have to know when to say "NO" and to stick by a particular outcome. Do not accept verbal abuse and inform a customer if his/her approach or tone is unacceptable, in a calm, firm and rational manner. Brown (2007) believes that it is not always possible to say "YES" to all customer requests but one should avoid saying "NO" and rather opt to say "I will see what I can do" instead.

Hoffman \& Bateson (2006) have uncovered seven categories that they classify as unsavoury behaviour from front line staff, these include: apathy, brush-off, coldness, condescension, robotism, rulebook and the runaround approach. LeClaire (2000) \& Vikesland (2002) found that in order to cope with negative employees management must offer to assist the employee either through training or by enquiring about the cause of the negativity but staff that already possesses a negative attitude should be motivated to change their behaviour. It is not always easy to find the right front line personnel. In many instances the wrong people are placed in the 'firing line' when they do not want to be there and are really not interested in customers, leaving the customer very disgruntled. Management has to take a fourfold approach to resolve the problem of finding the right person for the job. Firstly, considerable care must be taken in selecting the right type of person. This may include a strict selection process in which candidates with the appropriate qualities will be carefully considered. Candidates should be assessed on how they would handle a difficult customer. Overland (2005) and Twentyman (2008), view interview techniques as the best method of testing competency, where candidates are asked open ended questions to encourage them to talk about how they have coped with incidents in the past to obtain an inclination of how future situations will be handled.

Secondly, management has to train front line staff. Training should be done on an on-going basis, on various aspects of customer service and dealing with customers, like for instance how to be more friendly or attentive (Vikesland, 2002). Shelton (2003) undertook an audit of the service delivery levels at SABMiller, and found that Norman Adami the CEO's mission was to win the customers' favour and loyalty especially since Miller's market share was declining. Adami's turnaround strategy involved firing poorly performing executives and implementing a personnel rating system to ensure that all service staff worked to the best of their abilities, leaving no room for poor performers. SABMiller spent close to R154 million on training interventions to improve the level of service delivery and they enjoy a high staff retention rate as a result of their competitive salaries. As a general rule new staff has to undergo psychometric testing (Shelton, 2003). Thirdly, management has to monitor the progress of employees. This can be done by obtaining feedback from consumers about the level of service provided by a particular member of staff. Employees can also be observed by management on how they behaved in resolving a consumer query or complaint (Grote, 2005). Management needs to also include staff in the assessment by regularly asking them if they are coping. In the event of weaknesses, these can be resolved through training or other forms of support (Brown, 2007; Cavitt, 2010; Snow, 2007). SABMiller also has in place an Internal Management Process (IMP) which involves individuals meeting with managers on a monthly basis to discuss performance; in addition, annual performance reviews are held (Best Employer SA, 2008).

Finally, employees should feel comfortable enough to let management know if they are unhappy or uncomfortable in a front line position. If training has not proved to be a success then perhaps they can be moved to another position. Since much of the job of call centre agents involves liaising with customers via the telephone it is critical to understand what skills are needed to facilitate this form of communication as many 
agents do not undergo any form of formal training regarding proper telephone etiquette. In order to improve the level of service delivery many firms must introduce a service culture within the organisation. To achieve this, management has to select, motivate, reward, retain and unify good employees but in South Africa managers do not practice this (Blem, 1995). Service orientated companies have to perpetuate commitment and competence and this can be done by attracting, developing and keeping the right people, for example, at SABMiller every effort is made to maintain contact with past employees many of whom return to work at the firm. Incompetent people affect the culture of the firm negatively; therefore, extensive screening and interviewing should be undertaken to find the right fit.

Interpersonal skills, training and development: According to Blem (1995), in an attempt to increase productivity many firms have focused on two important questions being: How can we do it faster? How can we do it cheaper? But many fail to answer a third basic question of: How can we do it right the first time? The key to higher productivity lies in working better rather than faster. The payoffs for improving quality include:

- Lower costs: Doing things right the first time lowers the cost of materials, inspection and repairs.

- Worker pride: Doing things right the first time creates the positive feelings of confidence and success that come from mastering a job.

- Customer loyalty: Doing things right every time is the best way to ensure repeat business and attracting new customers. Research suggests that customers demand quality in future and not price in the purchase of goods and services, which they will be willing to pay for (Blem, 1995; Brown, 2007; Cavitt, 2010). In this regard, Blem (1995:51) believes that "The bitterness of poor quality lingers long after the sweetness of a cheap price is forgotten".

- Improving quality: How can quality be improved? The answer is simple: Ask the person who does the job how to improve it as he/she will have more insight into the job than anyone else. Worker participation should be encouraged at all stages.

In keeping with the theme of getting things done right the first time, International Business Machines (IBM) (2007) found that self-service portals can help build customer loyalty and improve satisfaction. If designed and deployed effectively, self-service portals can save a firm between fifteen to thirty percent by redirecting contacts, reducing call volumes and automating assistance. However, firms fear alienating customers and are unsure of how to create a positive experience; therefore, they are tentative about launching self-service portals. Overall, IBM (2007) found that if implemented correctly, self-service portals should provide users with quick and efficient information; portals must be interactive and should lower the costs of the firm. Dean (2008) offers a contrasting view to IBM's (2007) report. He found that although self-service systems experienced rapid growth, numerous customer complaints were lodged against the system. The basis of IVR is speech recognition accuracy and customers were experiencing recognition failures. In addition, there was a lack of choice to speak to a human consultant, background noise and static and the inability to understand customers who speak with an accent contributed to service failures. Dean (2008) concluded that the main driver behind IVR adoption was cost reduction rather than customer satisfaction.

Many business owners make and receive telephone calls on an ongoing basis but not many employees have professional telephone skills to make that first impression. Theron et al. (2003) and Ward (2010) identified the following collective weaknesses displayed by employees using a telephone:

- You cannot hear them

- You cannot understand them

- They cut you off when transferring you

- They speak down to you

- They use jargon when they talk to you

- They put you on indefinite hold

- They pass the buck to another person or department to solve the problem

- They provide misleading or erroneous information

- They may be rude

When the aforementioned telephone faux pas occurs, consumers will be left irate. Employees must realise that every time they receive a call they are the company to the other person on the line. Obviously a warm, 
friendly, sincere, courteous and tactful voice will make the customer's experience a positive one (Obarski, 2010). Since visual cues are not present in a telephone conversation, the employee has to harness their listening skills. Front line staff has to sound reassuring, interested and willing to help. It is essential for all telephonists or call centre agents to work out a telephone script which they can use to answer the phone. A script is a list of pre-prepared statements that a person can use when answering a call. For example, to welcome a caller, enquire what their problem is, direct the caller to a specific person, clarify a point or end the conversation.

Skills Required when Dealing with Telephone Calls: Theron et al. (2003) highlighted the following as key areas of focus in terms of how to improve an employee's professional telephone skill:

- Get ready: Sit up, take a deep breath as it relaxes and removes tension in your voice. Keep a paper and pencil at hand, together with forms that you may need. Be sure to record all necessary information legibly (Obarski, 2010).

- Put on a telephone face: Although nobody can see you smiling, there is a perception that smiling improves circulation and your emotional level; employees must be energetic.

- Answer the phone quickly: A general rule is that a phone must be answered on the third ring or in bigger environments within thirty seconds (Ward, 2010).

- The three part greeting: Always make sure that the first words that are spoken are your name, and the company or department you work for and an effective greeting. Identifying oneself enables the customer to reference his/her call with you later (Bailey \& Leland, 2008; Obarski, 2010).

- Speak clearly, naturally and distinctly: This is so obvious but is always ignored and very often when you call a company you do not understand the first sentence that came across the telephone line. This is due to people answering the phone in a robotic manner. Enunciate words and speak into the telephone. Speak slowly, loudly and distinctly (Ward, 2010).

- Listen: This is the best way to understand the customer's needs. Listen for at least seventy percent of the time and speak for thirty percent of the time. Some call centre operators though, tend to dominate the conversation overwhelming the customer. Ask questions related to the query to find a solution (Obarski, 2010).

- Ask for the customer's name early in the conversation. This gesture usually pleases customers. In some instances if a query cannot be handled on the spot and a referral is needed, the agent needs to know to whom he/she is speaking (Ward, 2010).

- Transferring calls: Politely place the caller on hold and ensure that if a call is transferred to another agent, then that agent is available and brief the agent on the customer's query so that the customer does not have to repeat himself/herself again (Bailey \& Leland, 2008).

- Take responsibility for the problem: As an agent take ownership of the matter. Respond appropriately to the consumer's needs immediately. Ask questions and if you need more time to resolve the query fully disclose this to the customer, taking down details and making sure to follow up.

- Be polite: Always be courteous and polite when dealing with frustrated consumers. Let them vent and then calmly restate the callers' issues in your own words. Irate people normally settle down fast and often thank employees for their understanding (Timm, 2008). Thoughtfulness and friendly interest is always needed to gain trust and goodwill of all people.

- Your facts database: A good call centre agent will try and have all facts at hand. He will also keep track of all enquiries. This personal 'facts database' helps deal with enquiries and keeps the agent on the ball. A database with frequently asked questions (FAQ's) is also recommended (Timm, 2008).

In the case of call centres, when a customer calls the company's care line or help desk the call is automatically logged on a computer as is the conversation. The operator records the customers' name, contact details and problem onto special software. According to Theron et al. (2003), the agent may be able to help the customer immediately or may refer the customer. When customers dial into a call centre their calls can also be answered by an automated service called an Interactive Voice Response facility (known as IVR), welcoming them to the company's call centre. This IVR will inform the customer that their call is important and to please be patient in waiting for the next available agent. In the meantime, the customer has the option to listen to promotional deals or other offerings made by the firm (IBM, 2007). Many consumers find the waiting tedious 
and frustrating and options that are offered do not cater for their specific needs. Another common frustration is that there is a lack of consistency when calling a call centre as you do not know which agent will receive your call and if this agent is efficient. Certain operators are trained to handle certain types of queries; this is the main purpose behind the menu options in an IVR system so that the customer is channelled to the right agents. Interestingly, Theron et al. (2003) have noted a marked increase in call centres in South Africa but emphasises that the country is falling short in terms of the people skills needed to implement and run such centres and the database technologies necessary to offer customer personalisation. This brings up a pivotal point in the discussion on striving for customer excellence which looks into how a service organisation can get its staff to give off their best at all times. In other words, understanding what characteristics staff perceive as appealing incentives to strive harder towards achieving the goals of the organisation.

Motivating Staff to Provide Excellent Service: According to Maslow's Hierarchy of Needs, all individuals have needs and motivation is the drive that compels individuals to take action to satisfy their needs. Indeed, different individuals are motivated by different things. In an article featured on Articlesbase (2006) managers are said to also be in need of motivation in order to inspire their staff. The article found that hiring motivated professionals is easier to manage than motivating professionals. For example, at Disney only people that love cleaning and sweeping are hired to clean the theme park which is immaculate. Implementation measures must be put into place to monitor and promote performance through appropriate remunerative rewards. Toolpack Consulting (2010) found that empowerment and job entitlement tend to increase motivation. Toolpack Consulting (2010) suggested that employees must be involved in decisions that affect them and that staff initiatives must be rewarded if they work in the firm's favour, as opposed to ordering staff to perform duties which creates social distance and should be avoided. According to Theron et al. (2003), some people may be easily motivated by financial gain and others by more time off. Motivation should be driven from the top down, but in the field of customer service, the individual service provider has to motivate itself to excel at the task of providing good service levels at all times, bearing in mind that customer service is often a thankless job. Theron et al. (2003:161) suggests that staff should try these 5 steps to start motivating themselves:

- Put up quotations that you find motivating around your workstation so that they are visible throughout the day.

- Develop a strong self-concept, because if you feel good about yourself this will impact on your performance.

- Set goals and do your best to achieve them.

- Read motivational books and messages that will make an impression on you.

- Have fun. The more fun you have, the more motivated you will be.

The need to acknowledge and appreciate the effort of staff by management can be highly motivating. Public commendation and praise can motivate even depressed customer service providers. Simple gestures like the ones listed below go a long way to creating happier staff:

- An extra 15 minutes given during break time by the boss to commend the effective handling of a customer.

- The entire group being rewarded with cakes because of excellent customer service.

- An agent receiving a personal note of thanks from the boss.

- An agent being given special mention in the firm's newsletter.

- An agent being allowed to leave early to avoid traffic.

These public 'rewards' appeal to one's need for recognition and motivates one to keep performing better each time.

Aim of the study: This study aims to assess customer perceptions of the impact of the sub-dimensions of human resources (skills, knowledge, ability, attitude; interpersonal skills and training and development) on call center agents in effectively managing their needs. 


\section{Methodology}

Respondents: The e-billing population of customers for the study comprised of 1847 customers in the Durban area. Using the Sekaran (2003) population-to-sample size table, a corresponding minimum sample of 317 was needed; however, only 220 responses were received. Probability sampling technique was used and simple random sampling was implemented for customers. The adequacy of the sample was determined using the Kaiser-Meyer-Olkin Measure of Sampling Adequacy (0.927) and the Bartlet's Test of Spherecity (1541.615, $p=0.000$ ) which, respectively, indicated suitability and significance. The results indicate that the normality and homoscedasticity preconditions are satisfied. In terms of the composition of the customer sample the majority of the respondents were males (55\%) compared to females (45\%). The majority of the sample were between the ages of 40-49 years (30\%) followed by 30-39 years (28.6\%) and then 50-59 years $(19.5 \%)$. Whites were the majority respondents of the customer questionnaire comprising $50.5 \%$ of the sample followed by Indians (32.7\%) and then Blacks (13.2\%). The majority of the respondents reported having a Diploma (34.1\%) followed by those with a degree (26.4\%) and a high school education (21.4\%).

Measuring Instrument: Data for the customers' questionnaire was collected using a self-developed, precoded, self-administered questionnaires consisting of two sections. Section A dealt with the biographical details (gender, age, race, education) of consumers participating in the study and was nominally scaled with precoded option categories. Section B tapped into customers' perceptions of the impact of the subdimensions of Human Resources (skills, knowledge, ability, attitude; interpersonal skills and training and development) on call center agents' in order to perform more effectively within the call center. Section B required respondents to rate each item using the Likert Scale ranging from strongly disagree (1) to strongly agree (5). The questionnaire was formulated on the basis of identifying recurring themes that surfaced while conducting the literature review. These ensured face and content validity. Furthermore, in-house pretesting was adopted to assess the suitability of both the instruments. Pilot testing was executed on the customer questionnaire to test the understanding of questions. No inadequacies were reported and the final questionnaire was considered appropriate in terms of relevance and construction.

Research procedure: The research was only conducted after ethical clearance was obtained for the study and upon completion of the pilot study.

Measures/statistical analysis of the questionnaire: The validity of the customers' questionnaire was assessed using Factor Analysis. A principal component analysis was used to extract initial factors and an iterated principle factor analysis was performed using SPSS with an Orthogonal Varimax Rotation. In terms of validity 3 critical factors were identified in influencing call center agents' effectiveness with latent roots greater than unity were identified $(4.474,2.203$ and 1.131). The items were also reflected as having a very high level of internal consistency and reliability, with the Cronbach's Coefficient Alpha being 0.927 with item reliabilities ranging from 0.913 to 0.933 .

Administration of the measuring instrument: The customer questionnaire was restricted to only those customers that subscribed to e-billing and had an email account. The online survey was administered to a sample of customers within the Durban region, South Africa using QuestionPro. Customers were required to completely answer Sections A and B of the questionnaire and then submit their responses via QuestionPro return mail. Informed consent was obtained by an authorization letter that accompanied the questionnaire. All participation was voluntary.

Statistical analysis of the data: Descriptive statistics (mean, measures of central tendency and dispersion) and inferential statistics (correlation, t-test, ANOVA) were used to evaluate the objectives and hypotheses for both questionnaires.

\section{Results}

Descriptive Statistics: Customers' perceptions of call center agents in effectively managing their needs were evaluated using a 1-5 point Likert scale. The higher the mean score value, the more satisfied the customers 
are with the performance of the agents in dealing with their queries and problems via the call center (Table 1).

Table 1: Descriptive Statistics: Customers' perceptions of the sub-dimension of Human Resource of Call Center Agents

\begin{tabular}{lllll}
\hline Sub-dimension & Mean & Std Deviation & Minimum & Maximum \\
\hline Skills, knowledge, ability, attitude performance & 2.683 & 0.9267 & 1.00 & 5.00 \\
Interpersonal skills & 2.636 & 0.8106 & 1.00 & 5.00 \\
Training \& development & 2.411 & 0.8377 & 1.00 & 5.00 \\
Overall score & 2.577 & 0.7990 & 1.00 & 5.00 \\
\hline
\end{tabular}

Table 1 indicates that customers' perceptions of the influence of the sub-dimensions of Human resource on call centre agents' effectiveness vary indicating that Skills, knowledge, ability, attitude (Mean $=2.683$ ) is critically lacking which will impact on performance. Even more unacceptable were the Interpersonal skills (Mean $=2.636$ ) which are deemed to be perilous to facilitate communication between customers and the organization and finally Training and development (Mean $=2.411$ ) ranked the worst against a maximum attainable mean score of 5; the study showed that most agents lacked the necessary training and sufficient development to execute their duties assiduously. In order to assess the areas for improvement, frequency analyses were conducted on each of the sub-dimensions. In terms of skills, knowledge, ability and attitude, $38.2 \%$ of the customers disagreed and a further $13.6 \%$ strongly disagreed that agents are extremely efficient in handling their queries or complaints efficiently. Furthermore, $34.5 \%$ of the customers disagreed and a further $10.5 \%$ strongly disagreed that agents try hard to resolve their query/complaint on the first call. In terms of interpersonal skills, $38.2 \%$ of the customers disagreed and another $16.4 \%$ strongly disagreed that they find communicating with an agent always being simple and straight forward. Furthermore, $38.2 \%$ of the customers disagreed and $26.8 \%$ of the customers strongly disagreed that agent's welcome feedback on how to improve their level of service delivery. In terms of the final sub-dimension of training and development, $32.3 \%$ of the customers disagreed and a further $15.9 \%$ strongly disagreed that they are seldom transferred to different agents none of whom can assist with their query. The implication is that customers are burdened with being transferred to other agents who try to assist with their queries. Furthermore, $38.2 \%$ of the customers disagreed and $39.1 \%$ of the customers strongly disagreed that agents always follow up to check if the customer was satisfied with their service performance.

\section{Inferential statistics}

Hypothesis 1: There exists significant intercorrelations amongst the sub-dimensions of human resources (skills, knowledge, ability, attitude; interpersonal skills and training and development) respectively.

Table 2: Pearson Correlation ( $r)$ : intercorrelations of the influence of Human Resource $(N=220)$

\begin{tabular}{lllll}
\hline Sub-dimension & $\boldsymbol{r} / \boldsymbol{p}$ & $\begin{array}{l}\text { Skills, knowledge, } \\
\text { ability, attitude }\end{array}$ & $\begin{array}{l}\text { Interpersonal } \\
\text { skills }\end{array}$ & $\begin{array}{l}\text { Training and } \\
\text { Development }\end{array}$ \\
\hline $\begin{array}{l}\text { Skills, knowledge, ability, } \\
\text { attitude in terms of }\end{array}$ & $\mathrm{p}$ & 1 & & \\
$\begin{array}{l}\text { communication } \\
\text { Interpersonal skills in terms }\end{array}$ & $\mathrm{r}$ & 0.844 & & \\
of communication & $\mathrm{p}$ & $0.000^{* *}$ & 1 & \\
Training and Development in & $\mathrm{r}$ & 0.752 & & \\
terms of communication & $\mathrm{p}$ & $0.000^{* *}$ & 0.804 & 1 \\
\hline
\end{tabular}

Note: ${ }^{* *} \mathrm{p}<0.01$

Table 2 indicates that the perilous constituents anticipated by customers in their interactions with call center agents significantly intercorrelate with each other at the $1 \%$ level of significance. Therefore, hypothesis 1 may be accepted. Table 2 indicates strong relationships between interpersonal skills in terms of communication and skills, knowledge, ability and attitude $(r=0.844)$ and training and development in terms of communication and interpersonal skills $(r=0.804)$, respectively. The significant intercorrelations between 
the perilous constituents of human resource indicates that if these abilities and attributes are enriched and developed it has the potential to have a positive spin off effect on the communication between the customer and the agents' thereby encouraging enhanced service delivery, greater customer satisfaction and enhanced overall efficiency.

Influence of Biographical data: The influence of the biographical variables (age, race, gender and education) on customers' perceptions of the sub-dimensions of ease of Human Resource was assessed using ANOVA and t-tests (Table 3).

Table 3: Biographical variables and the customers' perceptions of the sub-dimensions of Human Resource

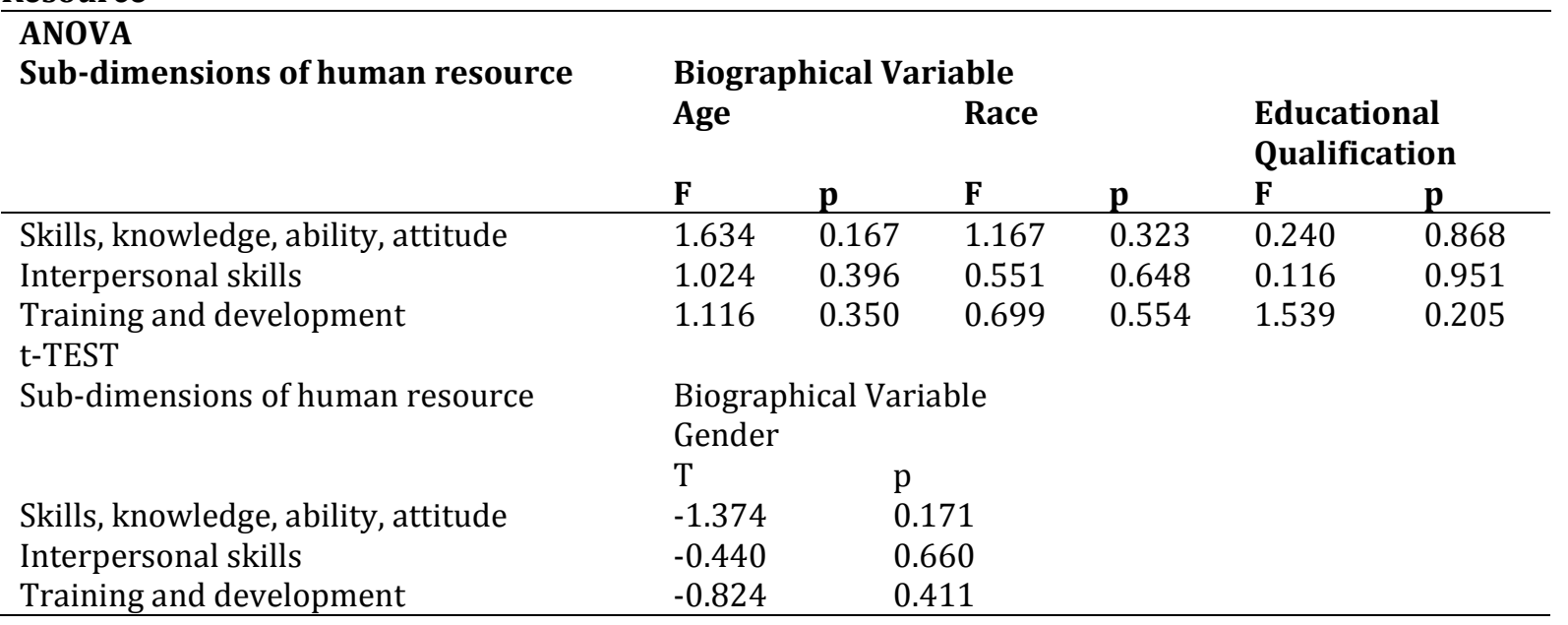

Hypothesis 2: Customers varying in biographical variables (age, race, gender and education) significantly differ in their perceptions of the sub-dimensions of human resource (skills, knowledge, ability, attitude; interpersonal skills and training and development) of call centre agents' respectively.

Table 3 indicates that customers varying in biographical profiles (age, race, gender and education) do not significantly differ in their perceptions of the sub-dimensions of human resource (skills, knowledge, ability, attitude; interpersonal skills and training and development). Hence hypothesis 2 may be rejected.

Hypothesis 3: The combined sub-dimensions (skills, knowledge, ability, attitude; interpersonal skills and training and development) significantly account for the variance in human resources when managing customers and their needs (Table 4).

Table 4: Multiple Regression: Customers' perceptions of the sub-dimensions of Human Resource

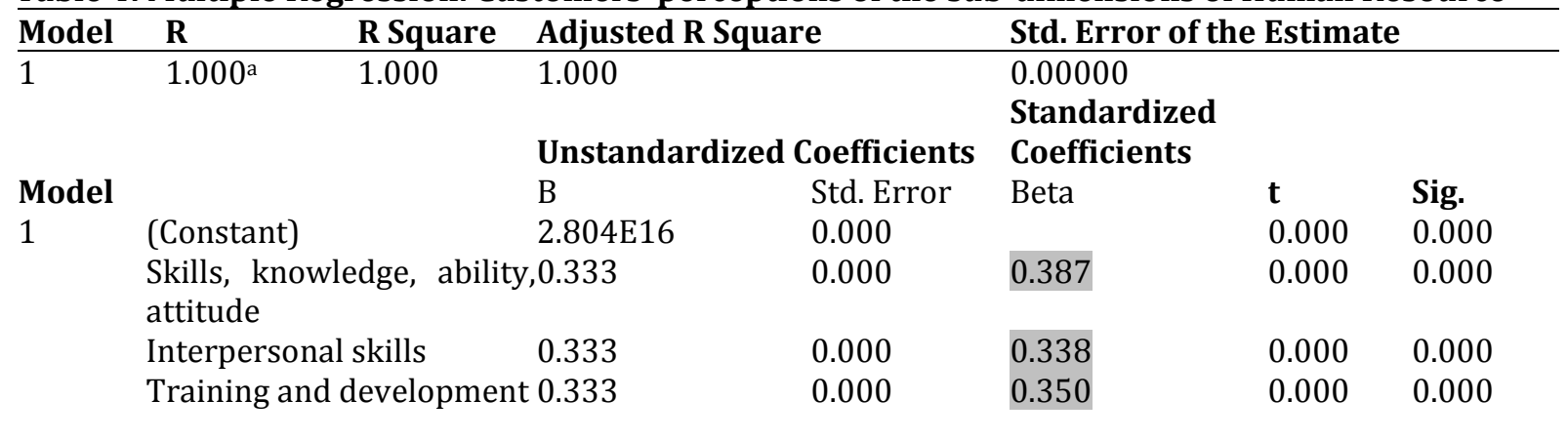

Table 4 indicates that the combined sub-dimensions account for $100 \%$ (Adjusted $\mathrm{R}^{2}=1.000$ ) of the variance in human resource when managing customers and their needs. Table 4 also specifies that these dimensions 
impact on customer perceptions of call centre agents' efficiency and performance when managing customers and their needs in varying degrees as indicated in the Beta values which are as follows:-

- $\quad$ Skills, knowledge, ability, attitude (Beta $=0.387$ )

- Training and Development (Beta $=0.350)$

- Interpersonal Skills (Beta $=0.338)$

Noticeably skills, knowledge, ability, attitude has the greatest impact whilst interpersonal skills has the slightest impact on human resources. The implication of this finding is that customers perceive the skills, knowledge, ability and attitude of call center agents to be of paramount importance in delivering a higher level of service delivery in satisfying their needs more efficiently but the interpersonal skills of agents' to enhance communication is deficient.

Discussion of Results: In terms of the sub-dimension of skills, knowledge, ability and attitude of agents and call centre effectiveness, the study reported that customers felt that the agents were not extremely effective in handling their needs and did not try hard to resolve their query/complaint. Eisengerich \& Bell (2006) concluded that agent's response speed and recovery initiation, which communicate empathy, effort and respect to the customer is critical in problem management. Customers evaluate the service encounter on the basis of interaction and quality of interpersonal treatment and communication. The flexibility and speed with which concerns are handled is identified as a vital dimension of procedural justice. Furthermore, Heskett, Sasser \& Schlesinger (1997) cautions that the longer the time taken to resolve customer concerns, the greater will be the customers' perception that procedural justice has been violated. Due to costs and time constraints and the effort involved with participation, customers will be less likely to make constructive suggestions and work with the firm if they perceive that the firm is not taking them seriously. Trends have displayed that while some customers prefer interactions through email, others still require the reassurance of speaking to a call center agent. Technology and media savvy consumers are further demanding communications through their mobile devices and social network accounts. Adhikari (2009) proposed that to enhance the communication between the organization and its consumers today, newer technology needed to be embraced such as Facebook, Twitter and Social blogging, as these are tools which are part of Customer Relationship Management strategies that assist in fostering better customer relationships going forward.

Despite the growing mix of customer engagement; many call centers are ill equipped to manage this myriad of interactions and most call center agents lack visibility into social media communications, as marketing has traditionally managed this medium. Thus it is essential to service customers on the channel of their choice and it is essential to equip agents with a multichannel desktop to enable them to service the customer efficiently and flexibly. In this way the organization is ensuring that customers are heard and responded to quickly and efficiently and improved call center agents' experience has an overall impact on improved customer experience (CRM Magazine, 2014). A unified, Omni-channel solution that empowers customers to transition from voice to mobile or text self-service or agent assisted service is the intelligent call center of the future. This will make the customer experience seamless on the backend and empowers the call centre agent with a powerful desktop, a cloud based system that serves the customer today (CRM Magazine, 2014).

In a study conducted by Mahesh and Kasturi (2006), key aspects of call center agents' job performance was explored and the key relationships between these aspects in relation to agents' effectiveness were tested. The results suggest that the key aspects of agents jobs were intrinsic motivation, reward/recognition/, customers stress and stress management. Their studies found a strong, positive and significant relationship between intrinsic motivation and effectiveness of agents especially for those agents who worked for a year or more on the job. In addition, customer stress was negatively correlated with intrinsic motivation while positively correlated with reward/recognition. Frontline employees represent the direct link between the organization and its customers in a service environment therefore a few researchers have sought to investigate these 'under- studied'; 'black-boxes' in this area of service management. One such researcher Singh (2000) remarked that frontline employees such as call center agents present interesting paradoxes, as these staff are usually underpaid, undertrained, overworked, highly stressed and under-studied. Another issue of innate concern in a call center was the call center agents' commitment and the high levels of withdrawal and turnover (Deery et al., 2002, Malhotra \& Mukherjee, 2004). Employee commitment encapsulates both agents' feelings about the organization and the desire to remain with it. In a similar study related to call centers 
Ruyter et al. (2001) found an inverse relationship between job satisfaction and employee turnover. Griffeth et al. (2000) found that employee commitment is a valid and reliable predictor of employee turnover. Hence employee commitment is important in the call center context as it reflects turnover intentions.

Mulholland (2002) examined the effectiveness of teamwork in call centers and its impact on employee performance by examining factors such as technical control, emotional labour and gender politics. Halliden \& Monks (2005) conducted a case study of a call center in Ireland and their findings suggest several ways to enhance employee performance. Varca (2006) researched how managerial observation of employees' performance impacted on employee stress. The findings support previous research emphasizing the importance of controlling tasks during service encounters in a call center and suggests that empowering call center agents' may help reduce job strain. In terms of the sub-dimension of interpersonal skills of agents and call center effectiveness, the study found that the customers reported that communicating with agents was not simple and that agents were not receptive to feedback on how they could improve their level of service delivery. Similarly, Davidow (2003) concluded that attentiveness comprising of four areas of respect, effort, empathy and willingness to listen impacts on customer satisfaction. Attitudes and behaviours of the service personnel stand out from the core service and have the potential to "make or break" the experience. Collie, Sparks \& Bradley (2000) found that courtesy and respect by service providers has a positive effect on outcomes fairness and satisfaction. Furthermore, Cho, Im \& Hiltz (2003) suggest that firms should place greater emphasis on rapid feedback on complaints. A synchronized feedback system is the quickest means of online communication. Online customer service centers and online chat services to their customers are more efficient and offer real time service that enables customers to solve problems/queries without delay. In another study conducted by Wallace, Eagleson \& Waldersee (2000), which tested efficiency versus service of call centre agents' their study found that efficiency and service is more conspicuous than in most other service delivery channels. Their study found that call center agents were required to take high numbers of calls whilst contributing to a significant amount of emotional labour, being helpful, friendly and empathetic towards customers. Call center agents had specific targets for talk-time, wrap-up-time and abandonment rates and supervisors measured agents in relation to service standards. Wallace et al. (2000) noted that agents were monitored in terms of performance objectives and performance management largely through meeting their numerical quotas and targets for efficiency and speed and although customer satisfaction was measured to a degree the former was more intentionally weighted. Clearly customer satisfaction although measured was not a priority in terms of assessing call center agents' performance on the job.

According to their research findings call center agents' respected that surface acting is inevitable because of the unpredictable nature of inbound calls. Agents are under repeated stress to sound impressive to customers who obviously do not appreciate their attempts. Call center agents further explained that the routinized nature of the work, scripted dialogue, low job control and repetitive call handling leads to mental exhaustion and job burnout (Akanji, Mordi \& Taylor, 2015). In terms of the final sub-dimension of training and development of agents and call center effectiveness, the findings of the study suggest that customers were burdened with being transferred to other agents to try and assist with their queries and that agents failed to always follow-up to check if the customers were satisfied with their service performance. Similarly, in their study Hoffman \& Bateson (2006) uncovered seven unsavory behaviour categories of front line staff, namely, apathy, brush-off, coldness, condescension, robotism, rulebook and the run-around approach. In some cases the way people are placed in call centers to handle customer queries and a complaint when they are not really interested in customers further exacerbates the situation. Theron et al. (2003) highlighted that among some of the critical skills that the customer service employees should possess is the habit to follow up with customers to enquire if they were satisfied with the outcomes provided. It may not be the solution the customer wants but it's a solution nevertheless. The high staff turnover rate in call centers has a cost impact on business and its stakeholders. This cost can be measured in terms of recruiting, inducting and training staff as well as in the indirect costs associated with erosion of customer service (Wallace et al., 2000).

Kinnie, Hutchison \& Purcell (2000) argue that it might be a challenge to attract highly committed and flexible staff and offer job security in an environment such as a call center where there is such high levels of surveillance and so little job discretion where customer service is expected and customer empowerment is increasingly sought. Emotional labour is the degree to which an individual expresses feelings or disguises 
feelings and behaviours in conformity for the firm's rules especially in treating customers (Walsh \& Bartikowski, 2013). Continuous intensity of emotional regulation can be draining on employees' behavior, performance and well-being (Kasabov \& Warlow, 2010). Two ways of performing emotional labour can be executed through surface acting and deep displays of feelings (Kinman, 2009, Wegge, Dick \& Bernstorff, 2010, Grandey, Diefendorff \& Rupp, 2013). Surface acting entails pretending to have the desired emotions to assist a customer. This can arise due to a lack of interest in the job or organization and high levels of burnout in call centre agents. Deep displays of feelings involves actual displays of sincere emotions in compliance with norms appropriate for executing the job (Akanji et al., 2015). In many instances surface acting is very common among call center agents.

\section{Recommendations and Conclusion}

Customers found agents to be extremely ineffective in handling their needs and agents did not try to resolve their query/complaint promptly. Part of the service delivery process within most global call centers is to try and resolves queries and complaints within the first-call. However this was clearly not achieved within this study and clearly presented a gap in terms of the service delivery process. Customers found communicating with agents difficult and agents were not receptive to feedback on how they could improve their performance delivery. There are no guidelines when it comes to dealing with a customer as each set of circumstances is unique and it depends on the agent's expertise and their ability to remain proficient under extreme pressure. Informal sessions where agents share their competencies with each other on how to manage challenging customers is very productive and helpful especially for new agents just commencing their careers within the call center. Whilst most call centers do have self-service technology for customers to download or access the information that they require themselves; most customers often opt to wait on the line to liaise with an agent but the communication process is often difficult due to poor interpersonal skills of agents. It is recommended that all call center agents undergo multilingual training and should be fully conversant in different languages. Agents should also be fully computer literate as World Class call centres adopt cutting edge technology to facilitate operational efficiency and these agents should be proficient in operating the technology efficiently. This has been further reinforced by research whereby the call center agent is technologically empowered with a multichannel desktop to be able to service the customer using the channel of the customer's choice allowing for switching between different channels of communication with ease and the least disruption to the call/query. Brands that are considering delivering an astonishing customer experience across multiple channels need to integrate both existing and past customer communications across all channels including voice, chat, email, and social networks, and package it all on a single screen.

Customers felt burdened by being transferred to other agents often and agents failed to follow up to check if they were satisfied with the service delivery. There is much debate surrounding the level of authorization afforded to call center agents in terms of the level of authority and responsibility delegated to them in order to effectively resolve a query themselves without having to attain permission from a superior or to transfer that call to a supervisor or line manager. This would certainly reduce the waiting times of customers for the resolution of queries as well as the continual transfer between agents before a resolution is reached. The nature of the work within a call center environment proves to be a challenging encounter to entice exceedingly dedicated and flexible staff and offer job security in an environment such as a call center where there are such great levels of surveillance and such diminutive job discretion, where customer service is expected and customer empowerment is increasingly sought. Research strongly supports the call for greater autonomy of call center agents in allowing them to perform their jobs more efficiently, less surveillance and monitoring by supervisors and measuring agents' performance management through more meaningful objectives such as customer satisfaction indicators and not so much on meeting the numerical and operational quotas within the center. In this way the agent strives to build a better relationship with the customer and can focus on the call and the customers' needs and is not under pressure to meet numerical quotas and targets imposed on them. Customer service delivery is certainly never a simple task to administer and customers need assurances that they are valued members of the organization. In the end, it all comes down to this: A Better Call Centre Agent Experience $=$ A Better Customer Experience $=$ Better Customer Lifetime Value. Businesses need to regularly ensure that customers are happy, agents must be courteous, receptive to comments and suggestions on how to improve performance and ensure that customers are 
satisfied at the end of the business transaction with the call center. The entire service delivery process must be executed efficiently and effectively with a guarantee to customers that the firm is committed to customer care in the long run.

Recommendations for Future Research: This study has been undertaken in one public service call center and hence, the results of the study have internal validity to this organization. In order to enhance generalizability, it would be useful to undertake a similar study in other call center environments in a variety of service environments in both the public and private sectors. This study also includes a call center environment where only in-bound calls are made and hence, it would be useful to assess similar dimensions in an out-bound call settings as speaking to someone who has chosen to interact with you is completely different from speaking to someone who was not expecting your interaction.

\section{References}

Adhikari, R. (2009). Why business needs a CRM Strategy. Available at http://www.internetnews.com/webcontent/article.php/3800911.

Akanji, B., Mordi, C. \& Taylor, A. (2015). The nature and outcomes of emotion in customer service management. Economic Insights - Trends and Challenges, 4(LXVII), 13-21.

Articlesbase. (2006). Four ways to motivate service professionals - guide to getting wow performance. Available at http://www.articlesbase. com/leadership-articles/four-ways-to-motivate-serviceprofessionals-a-guide-to-getting wow-performance-61886.html.

Bailey, K. \& Leland, K. (2008). Customer Service in an Instant: 60 Ways to Win Customers and keep them coming Back. Franklin lakes: Career Press Inc.

Bannatyne, D. (2010). Twitter and Facebook can improve customer service. Available at http://www.telegraph.co.uk/finance/jobs/duncan-bannatyne/7206420/twitter-and-facebook-canimprove-customer-service.

Best Employers: SA. (2008). SAB Limited. Available at http://www.bestemployers.co.za /Company \%20profiles/BEST\%20EMPSAB.pdf.

BizAssist Technologies (PTY) Ltd. (2009). The 10 Commandments of Customer Service. Available at http:// www.bizassist.co.za /news.asp?Head=\&cat=start\&Ref $=460$.

Blem, N. (1995). Service Please South Africa. RSA: Juta \& Co, Ltd.

Brown, L. (2007). What your Customers Really want: 7 qualities of customer care. Available at http://www.allbusiness. com/sales/4493484-1.html.

Cant, M., Brink, A. \& Brijball, S. (2006). Consumer Behaviour. Cape Town: Juta \& Co. Ltd.

Cavitt, C. (2010). Improve on your customer service - The 5 outstanding qualities of a service superstar. Available at http://ezinearticles.com/? Improve-on-Your-Customer-Service---The-OutstandingQualities-of-a-Service-Superstar \&id = 141561 .

Cho, Y., Im, I. L. \& Hiltz, R. (2003). The impact of e-services failures and customer complaints on electronic commerce Customer Relationship Management. Journal of Consumer Satisfaction, Dissatisfaction and Complaining Behaviour, 16, 106-118.

Collie, T. A., Sparks, B. \& Bradley, G. (2000). Investing in International Justice: a study of fair process effect within a hospitality failure context. Journal of Hospitality and Tourism Research, 24(4), 448-472.

CRM Magazine. (2014). Deploying an intelligent contact centre in the cloud. WP 24.

CRM Magazine. (2014). Empower your agents to deliver exceptional Omnichannel customer experience.

Davidow, M. (2003). Organizational responses to customer complaints: what works and what doesn't. Journal of Service Research, 5(3), 225-250.

Dean, D. H. (2008). What's wrong with IVR self-service. Available at http://proquest.umi.com/pqdweb?index=7\&did=160082 8341\&SrchMode=1 \&sid= $\quad 4 \&$ Fmt $=3 \&$ VInst $=$ PROD\&V Type $=P$ Q D\& RQT $=309 \&$ V Name $=$ PQD\&TS $=1268381826 \&$ clienId $=30$ 060 .

Deery, S., Iverson, R. \& Walsh, J. (2002). Work relationships in telephone call centre's: understanding emotional exhaustion and employee withdrawal. Journal of Management Studies, 39(1), 471-496.

Donaldson, B. \& O' Toole, T. (2002). Strategic Market Relationships: from strategy to implementation. Shannon England: John Wiley \& Sons Ltd. 
Eisingerich, A. B. \& Bell, S. J. (2006). Relationship Marketing in the financial services industry: The importance of customer education, participation and problem management for customer loyalty. Journal of Financial Services Marketing, 10(4), 86 - 97.

Gabbott, M. \& Hogg, G. (1998). Consumers and Services. England: John Wiley \& Sons Ltd.

Goodman, J. A., Broetzmann, S. M. \& Adamson, C. (1992). Ineffective - that's the problem with customer satisfaction surveys. Quality Progress, 5, 35-38.

Grandey, A. A., Diefendorff, J. M. \& Rupp, D. E. (2013). Emotional labour in the $21^{\text {st }}$ Century: Diverse perspective on emotion regulation at work. New York. Psychology Press: Routledge.

Griffeth, R. W., Hom, P. W. \& Gaernter, G. (2000). A meta analysis of antecedents and correlations of employee turnover. Journal of Marketing, 26(3), 463-488.

Grote, D. (2005). Attitude adjustments: to deal with an employee's bad attitude, focus on his or her specific behaviors. Available at http://findarticles. com/p/articles/mi_m 3495/is_7_50/ai_n14814551/.

Halliden, B. \& Monks, K. (2005). Employee centered management in a call centre. Personnel Review, 34(3), 370-383.

Heskett, J. L., Sasser-Jr., W. E. \& Schlesinger, L. A. (1997). The service profit chain: how leading companies link profit and growth to loyalty, satisfaction and value. The Fine Press. New York.

Hoffman, K. D. \& Bateson, J. E. G. (2006). Services Marketing: Concepts, Strategies \& Cases. Third Edition. USA: Thomson South - Western.

Hoyer, W. D. \& McInnis, D. J. (2001). Consumer Behaviour. Second Edition. USA: Houghton Mifflin Company.

IBM. (2007). Improving business productivity and client satisfaction with customer and partner self - service portals. Available at ftp://ftp.software.ibm.com/software /lotus/pub/lotusweb/Customer_Self_Service_white_paper.pdf.

Jack, E. P., Bedics, T. A. \& McCary, C. E. (2006). Operational Challenges in a call centre industry: a case study and resource-based framework. Managing Service Quality, 16(5), 477-500.

Kasabov, E. \& Warlov, A. J. (2010). Towards a new model of customer compliance service provision. European Journal of Marketing, 44(6), 700-729.

Kinman, G. (2009). Emotional labour strain in frontline service employees. Does mode of delivery matter? Journal of Managerial Psychology, 24(2), 118-135.

Kinnie, N., Hutchison, S. \& Purcell, J. (2000). Fun and surveillance: the paradox of high commitment management in call centres. The International Journal of Human Resource Management, 11(6), 967985.

Lamb, C. W., Hair, J. F., McDaniel, C., Boshoff, C. \& Terblanche, N. S. (2000). Marketing. Cape Town: Oxford University Press Southern Africa.

LeClaire, J. (2000). Checklist: hire and train your customer service staff. Available at http://www.inc.com/articles/ 2000/ 04/18319.html.

Little, M. M. \& Dean, A. M. (2006). Links between service climate, employee commitment and employees service quality capability. Managing Service Quality, 16(5), 460-476.

Lovelock, C. (2001). Services Marketing: People, Technology, Strategy. Fourth Edition. USA: Prentice Hall.

Lucas, R. W. (2005). Customer Service: Building successful skills for the $21^{\text {st }}$ Century. Third Edition. New York: McGraw-Hill/Irwin.

Mahesh, V. K. \& Kasturi, A. (2006). Improving call centre agent performance: A UK-India study based on the agents point of view. International Journal of Service Industry Management, 17(2), 136-157.

Malhotra, N. \& Mukherjee, A. (2004). The relative influence of organizational commitment and job satisfaction on service quality of customer contact employees in banking call centres. Journal of Services Marketing, 18(3), 162-174.

Miller, A. (2010). Exceptional customer service - How do you thank your customers? Available at http://ezinearticles.com/?Exceptional-Customer-Service---How-Do-YOU-Thank-Your Customers?\& id $=3889364$.

Mulholland, K. (2002). Gender, emotional labour and teamworking in a call centre. Personnel Review, 31(2), 283-303.

Oakland, J. S. \& Beardmore, D. (1995). Best Practice Customer Service. Total Quality Management, 6(2), 135148.

Obarski, A. M. (2010). How to Improve Your Telephone Skills. Available at http://www.businessknowhow. com/ marketing/ telephone-skills.htm. 
Oneayso, G. (2007). Are customers' Dissatisfaction and Complaint Behaviours Positively Related? Journal of American Academy of Business, 11(1), 18-24,Cambridge.

Overland, H. M. (2005). Top 10 tips for hiring technical staff. Internet. Retrieved from the World Wide Web: http://www.mssem.com/library/hiring_guide_top_10.html.

Peters, T. J. \& Waterman, R. H. (1982). In Search of Excellence. New York: Harper \& Row.

Rust, R. T., Zahorik, A. J. \& Keiningham, T. L. (1996). Service Marketing. New York: HarperCollins College Publishers.

Sekaran, U. (2003). Research Methods for Business: A Skills Building Approach. Fourth Edition. USA: John Wiley \& Sons, Inc.

Singh, J. (2000). Performance productivity of quality of frontline employees in service organizations. Journal of Marketing, 64(2), 15-34.

Snow, D. (2007). Professionalism equals more than just doing your job. Available at http://www.rediff.com/money/2007/jul/24prof.htm.

Stirtz, K. (2010). Three things you can do to improve customer service. Available at http://www.allbusiness.com/company-activities-management/operations-customer/139755631.html.

Theron, D., Bothma, C. \& Du Toit, M. (2003). Focusing on Customer Service in Southern Africa. Pretoria: Prince Publishers.

Timm, P. R. (2008). Customer Service: Career Success through Customer Loyalty. Fourth Edition. USA: Pearson Prentice Hall.

Toolpack Consulting. (2010). Fighting apathy with engagement. Available at http://www.toolpack.com/motivate.html.

Twentyman, J. (2008). How to hire the right staff. Available at http://www.scmagazineuk.com/recruitmenthow-to-hire-the-right-staff/article /110130/.

Varca, P. E. (2006). Telephone surveillance in call centres: prescriptions for reducing strain. Managing Service Quality, 16(3), 203-219.

Vikesland, G. (2002). Dealing with the negative employee. Available at http://www.employeremployee.com/october2002tips.html.

Wegge, J., Dick, R. V. \& Bernstorff, C. (2010). Emotional dissonance in call centre work. Journal of Managerial Psychology, 25(6), 569-619.

Wallace, C. M., Eagleson, G. \& Waldersee, R. (2000). The sacrificial Human Resource strategy in call centres. International Journal of Service Industry Management, 11(2), 174-184.

Walsh, G. \& Bartikowski, B. (2013). Employee emotional and quitting intentions: moderating effects of gender and age. European Journal of Marketing, 47(8), 1213-1237.

Ward, S. (2010). How you answer your phone says a great deal about your business. Available at http://sbinfocanada.About.com/cs/ management/qt/telephonetips.htm.

Zeithaml, V. A. \& Bitner, M. J. (2003). Services Marketing: Integrating Customer Focus Across the Firm. Third Edition. New York: McGraw-Hill.

Zeithaml, V. A., Bitner, M. J. \& Gremler, D. D. (2006). Services Marketing: Integrated Customer Focus Across the Firm. Fourth Edition. New York: McGraw-Hill/Irwin.

4-R Marketing LLC. (2009). 4-R Marketing Model. Available at http://4rmarketing.com/4Rmodel.htm.

12 manage - The executive Fast Track. (2009). Comparing Service Quality Performance with Customer Service Quality Needs. Available at http://www.12manage.com/methods_zeithaml_servqual. html. 